\title{
Compound testing of individually conditioned stimuli as an index of
excitatory and inhibitory properties
}

\author{
D. REBERG and A. H. BLACK, McMaster \\ University, Hamilton, Ont., Canada
}

In a classical conditioned-suppression procedure, two CSts, when prosented in compound, produced more suppression than either alone; $a C S+$ and a $C S-$, when presented in compound, produced less suppression than the CSt alone; and a compound consisting of CSt and a "neutral" $C S^{\circ}$ produced suppression which did not differ from CSt alone. The differential effects of the compounds permit one to measure excitatory or inhibitory properties of a $C S$.

In this research we were interested in the effects of compound presentations of two classically conditioned stimuli (CSs) after training procedures in which either (a) both had been paired with an unconditioned stimulus(US), or (b) one stimulus (CS+) was paired with the US while the second stimulus (CS-) was not. We hoped that a comparison of these compounds would permit us to assess the excitatory and inhibitory properties of their elements in a manner similar to that employed by Cornell \& Strub (1965) for discriminative stimuli in operant conditioning situations.

\section{EXPERIMENT 1}

Each of two CSs was separately paired with a shock US while rats pressed a lever for food reinforcement. Suppression of bar pressing produced by each CS and by the compound of both CSs was then measured. Since any enhanced suppression to the compound could not be observed when suppression to the individual CSs was complete, compound tests were made in early acquisition and early extinction when some responding to each of the CSs occurred.

\section{Subjects}

The Ss were 18 male hooded rats, maintained at $75 \%$ of their ad lib body weights throughout the experiment.

\section{Apparatus}

The apparatus consisted of standard Skinner boxes, individually housed in sound-reducing chambers. The two stimuli employed as CSs were darkness (D), produced by turning off the 6 -W houselight, and a $70-\mathrm{dB}$ white noise $(\mathrm{N})$. The shock was obtained at the $1.0-\mathrm{mA}$ setting on Grason-Stadler shock generators.

\section{Procedure}

The Ss received five daily 2 -h sessions of bar-press training in which food pellets were delivered on a VI 3-min schedule. Two pretest trials of each of N, D, and the N/D compound were given on the following session. Two days of conditioning followed. On each day, two 90-sec presentations of $\mathrm{N}$ and two of $D$ were scheduled at randomly selected intervals. Shock was programmed during the last $.5 \mathrm{sec}$ of each CS. Order of presentation of the CSs was counterbalanced.

The data were described in terms of suppression ratios according to the formula $B /(A+B)$, in which $A=$ number of responses during the $90 \mathrm{sec}$ immediately preceding $C S$ onset and $B=$ the number of responses recorded in the presence of the 90-sec CS.

Compound tests were made at two points: (1) An unreinforced test trial was scheduled for all Ss at the end of the first conditioning session. Six Ss were tested with $N$, six with $D$, and six with the N/D compound. (2) Compound tests were scheduled for 13 rats following the satisfaction of an extinction criterion, defined as follows: for each $S$, unreinforced presentations of one CS were repeated at 5-min intervals until the suppression ratio reached .20 or above. The other $C S$ was then presented repeatedly until the .20 criterion was satisfied, whereupon the first stimulus was tested again to insure that it still exceeded the .20 criterion. The compound was then presented. Each of the individual stimuli was presented once more following the compound test.

\section{Results}

The results for both acquisition and extinction are presented in the upper half of Fig. 1. In acquisition, all six $S s$ tested with the compound showed greater suppression to the compound than to either of the preceding single-stimulus trials. This pattern was duplicated by only two of six Ss tested with $\mathrm{N}$, and two of six tested with $\mathrm{D}$. The differences between the compound test stimulus and the more suppressed of the preceding single stimuli were significantly greater than the corresponding differences for either of the single-stimulus test groups [Whitney's extension of the Mann-Whitney U test, $\operatorname{Pr}(h=2.40), \operatorname{Pr}(h=2.64)<.01]$. In extinction, 11 of 13 Ss showed greater suppression to the compound than to any of the individual stimuli immediately preceding and following it. ${ }^{2}$ EXPERIMENT 2

In the second experiment, a compound consisting of CSt and CS- from a differential conditioning situation was studied. Since the effects of a compound could be produced by some nonassociative factor such as "novelty," a compound consisting of a CSt, and a "neutral" stimulus $\left(\mathrm{CS}^{\circ}\right)$ was also studied.

\section{Subjects}

The Ss were 24 male hooded rats, deprived and maintained as in Experiment 1. One $\mathrm{S}$ died before the experiment was completed, and the data from two others were discarded because of very low VI baselines.

\section{Apparatus}

The apparatus was that used in Experiment 1. The conditioned stimuli were darkness and $80-\mathrm{dB}$ white noise. US intensity was that produced at the $1.3-\mathrm{mA}$ setting of the shock generators. For each $S$, either $\mathrm{D}$ or $\mathrm{N}$ was selected as $\mathrm{CS}+$. The other stimulus served as CS- for differential Ss and $\mathrm{CS}^{\circ}$ for nondifferential Ss.

\section{Procedure}

The pretest CS presentations, food-reinforcement schedule, and the temporal parameters of classical conditioning were the same as in Experiment 1. Conditioning took place over 4 consecutive days. On each of the first 2 days, three shock-terminated CS+ presentations were scheduled. On the third

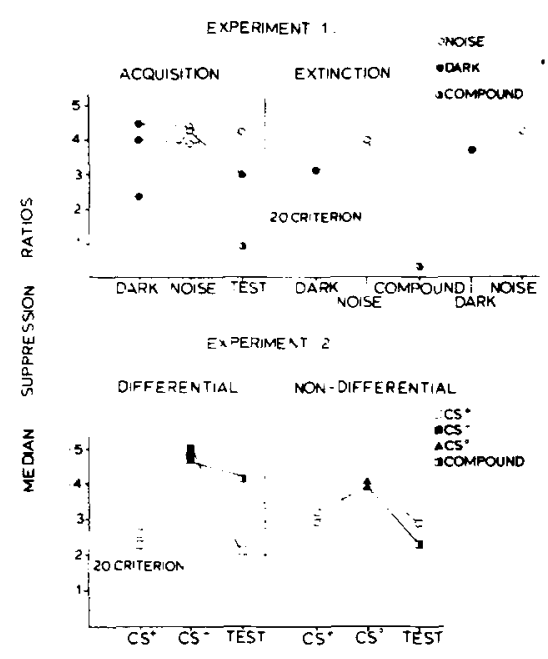

Fig. 1. Suppression ratios for single CSs and compound CSs in Experiment 1 (upper portion) and Experiment 2 (lower portion) are shown. In Experiment 1, the order of single-stimulus presentations was counterbalanced. The lines joining certain points indicate that the joined data points are from one group of Ss. 
and fourth days, the differential training groups received three $\mathrm{CS}+$ trials paired with shock, and three CS presentations never paired with shock. Nondifferential Ss continued to receive only three reinforced CS+ trials on each of the last 2 days of training. No stimulus presentations were made during the session following the completion of training in order to allow bar-pressing baselines to recover.

Extinction began on the next session. For the differentially trained $S s$, four extinction trials of CS+ were scheduled daily, until the .20 criterion was satisfied. On the next trial, a CS- was presented, followed by a test trial on which CS+ was presented for half the Ss and the $\mathrm{CS}+/ \mathrm{CS}$ - compound for the other half.

On the following day, CS+ was presented again. When the .20 criterion was met within four trials, a $\mathrm{CS}$ - trial followed, in turn succeeded by either $\mathrm{CS}+$ or $\mathrm{CS}+/ \mathrm{CS}-$, whichever had not been tested on the previous day. The same procedure served for the nondifferential group, with $\mathrm{CS}^{\circ}$ replacing $\mathrm{CS}-$.

\section{Results}

Both groups of Ss showed almost complete suppression by the second day of acquisition. No significant suppression to the $\mathrm{CS}$ - occurred when it was introduced on Day 3 of acquisition. By Day 4, however, differential Ss exhibited significant acceleration to $\mathrm{CS}$ - (median Day $4 \mathrm{CS}-$ ratio $=.56, \quad$ Wilcoxon $\mathrm{T}=2, \mathrm{n}=11$, $\mathrm{p}<.01$ ), indicating that $\mathrm{CS}-$ had an effect on responding different from that of the background stimuli.

The results of both test blocks for the differential and nondifferential groups are shown in the lower section of Fig. 1. The three points on each curve represent the CSt criterion trial, the subsequent $\mathrm{CS}-$ or $\mathrm{CS}^{\circ}$ trial, and the tests of either CS+ or the appropriate compound. For all $S$ s in the differential group, the compound produced less suppression than the test $\mathrm{CS}+$ (Wilcoxon $t=6.5, n=11, p<.05$ ); for Ss in the nondifferential group, there was no significant difference between compound and test CSt. Furthermore, the magnitude of the difference between test CS+ and compound was significantly greater for differential Ss than for nondifferential Ss (Mann-Whitney $U=26.5, n=21, p<.05$ ).

$$
\text { DISCUSSION }
$$

When the results of the two experiments are combined, they indicate that (1) two $\mathrm{CS}+\mathrm{s}$, when presented in compound, produce more suppression than either alone; (b) a CSt and a CS-, when presented in compound, produce less suppression than the CSt alone; and (c) a compound consisting of CSt and a "neutral" $\mathrm{CS}^{\circ}$ produces suppression which does not differ from CS+ alone. Furthermore, these results were obtained after relatively little training, in contrast to other experiments which studied compounds of CS+s (Miller, 1969) and of a CSt and CS- (Hammond, 1967) after extensive single-stimulus training.

These data indicate that the same results are obtained for compounds of classically conditioned stimuli as for compounds of operantly conditioned stimuli (Comell \& Strub, 1965). Furthermore, the inclusion of the $\mathrm{CS}+/ \mathrm{CS}^{\circ}$ compound in the present experiment permits one to rule out certain interpretations of the data. The possibility that the effect of either compound stimulus could be accounted for by some "novelty" effect leading to increased suppression, or generalization decrement leading to decreased suppression, is not supported by the outcome of the second experiment. Novelty, or generalization decrement, should have led to a change in responding to the $\mathrm{CS}+/ \mathrm{CS}^{\circ}$ compound as well as to the $\mathrm{CS}+/ \mathrm{CS}-$ compound. This did not occur. The simplest and most compelling explanation of the data is that the effect of a compound is produced by some combination of excitatory strengths tending to suppress bar pressing, and inhibitory strengths tending to attenuate the suppression. If this explanation is correct, the compound procedure will permit one to determine the excitatory or inhibitory properties of an unknown stimulus, as do the conditioned-inhibition (Pavlov, 1927; Brown \& Jenkins, 1967) and the generalization of inhibition (Jenkins, 1965) techniques. If it is excitatory, a compound of the unknown stimulus and a CS+ should produce more suppression than either stimulus alone; if it is inhibitory, the compound should produce less suppression than the CS+

\section{REFERENCES}

BROWN, P. L., \& JENKINS, H. M. Conditioned inhibition and excitation in operant discrimination learning. Journal of Experimental Psychology, 1967, 75, 255-266. COR NELL, J. M., \& STRUB, H. A technique for demonstrating the inhibitory function of $S \Delta$ Psychonomic Science, 1965, 3, 25-26.

HAMMOND, L. J. A traditional demonstration of the active properties of Pavlovian inhibition using differential CER. Psychonomic Science, 1967, 9, 65-66.

JENKINS, H. M. Generalization gradients and the concept of inhibition. In D. J. Mostofsky (Ed.), Stimulus generalization. Stanford: Stanford University Press, 1965.

MILLER, L. Compounding of pre-aversive stimuli. Journal of the Experimental Analysis of Behavior, 1969, 12, 293-299.

PAVLOV, I. P. Conditioned reflexes. London: Oxford University Press, 1927. NOTES

1. The research described in this paper was supported by funds from Research Grants No. 258 from the Ontario Mental Health Foundation and No. APA 42 from the National Research Council of Canada to A. H. Black. We thank Mrs. H. Santa-Barbara for her editorial assistance.

2. Examination of VI baselines turoughout the conditioning and extinction sessions revealed no systematic difference which could account for the test trial outcomes. This was also true of the second experiment.

\section{Conditioned suppression on a fixed interval schedule of reinforcement ${ }^{1}$}

DAVID O. LYON and RICHARD D. MILLAR, Westem Michigan University, Kalamazoo, Mich. 49001

The key-pecking behavior of two pigeons was maintained on a 2-min fixed-interval schedule of reinforcement. The interval was divided into four 30-sec periods, and an Estes-Skinner conditioned-suppression procedure was superimposed on the second, third, and fourth 30-sec periods of the fixed interval. Suppression was obtained during the second 30-sec interval, but a complete loss of suppression was obtained when the CS was presented during the last 30-sec period prior to a reinforcement. The results serve to complete the generalization that the severity of conditioned suppression on fixed schedules of reinforcement is determined in part by the temporal relationship between the CS onset and the presentation of a reinforcement.

The present study was designed to measure changes in the severity of conditioned suppression as a function of the placement of the preshock stimulus within a fixed-interval schedule of reinforcement. The behavioral effect of conditioned suppression is defined as a decrease in the rate of a positively reinforced response during a stimulus (CS) which precedes shock (Estes \& Skinner, 1941). The defining characteristic of the procedure is that the stimulus and shock are superimposed on the baseline independently of the baseline performance. 